\title{
Survey of BK Virus in Renal Transplant Recipients in Iran: A Systematic Review and Meta-Analysis
}

\author{
Somayeh Shatizadeh Malekshahi ${ }^{a}$ Hoorieh Soleimanjahi ${ }^{a}$ Fariba Dorostkar $^{b}$ \\ Vahid Salimi $^{\text {b }}$ Mohammad Farahmand $^{\text {b }}$ \\ aDepartment of Virology, Faculty of Medical Sciences, Tarbiat Modares University, Teheran, Iran; \\ bVirology Department, School of Public Health, Tehran University of Medical Sciences, Teheran, Iran
}

\section{Keywords}

BK virus · Renal transplantation - Meta-analysis · Systematic review · Epidemiology · Infectious disease · Virology

\begin{abstract}
Introduction: BK virus (BKV) infection in renal transplant (RT) recipients can cause hemorrhagic cystitis, transient renal dysfunction, and BKV nephropathy (BKVN). The prevalence and significance of BKV in $\mathrm{RT}$ recipients remain to be clarified in the Iranian population. The purpose of this review is to summarize the overall prevalence of BKV infection in RT recipients from previously published studies in Iran. Methods: We systematically reviewed articles through a comprehensive search of the main electronic and Persian national databases up to November 2019. Results: The overall pooled prevalence of BKV infection among the Iranian population was $23 \%$ (95\% Cl; $15-33 \%)$. Comparing these studies revealed that the prevalence of BKV in plasma samples ranges from 3 to $40 \%$, in renal biopsies 1-13\%, and in urine samples $10-49 \%$. Due to substantial heterogeneity among reported studies $\left(I^{2}=93 \%, p<0.01\right)$, random-effect meta-analysis was performed. BKV infection rate was slightly higher in women than men ( $16 \%, p=0.04$ vs. $14 \%, p<0.01$, respectively). The
\end{abstract}

majority of the studies employed real-time PCR $\left(24 \%, I^{2}=93\right.$, $p<0.01)$ and analyzed plasma samples alone or in combination with other types of specimens. BKV prevalence from 5 cities among the Iranian population showed a higher prevalence rate in Guilan. Conclusion: Our analysis provides a preliminary estimate of the epidemiology of BKV infection in RT recipients in Iran. These results arouse a need for more epidemiological studies of BKV infection in different unanalyzed regions in Iran. Early detection of BKV in RT recipients helps timely nephropathy diagnosis and prevents graft loss.

(c) 2020 S. Karger AG, Basel

\section{Introduction}

$\mathrm{BK}$ virus $(\mathrm{BKV})$ is a ubiquitous, small, and nonenveloped DNA virus that belongs to the polyomaviridae family [1]. BKV infects the majority of the population in the first decade of life and usually is asymptomatic or associated with fever and mild upper respiratory symptoms [2]. After primary infection, BKV enters a latent state and resides in the renal tubular and uroepithelial cells, where its intermittent reactivation leading to asymptomatic viruria in $7-15 \%$ of healthy subjects [3]. Reactivation of BKV ap- karger@karger.com www.karger.com/int

(C) 2020 S. Karger AG, Base

Karger"
Mohammad Farahmand

Virology Department, School of Public Health

Tehran University of Medical Sciences, Porsina Ave., Keshavarz Blvd Tehran 1471613151 (Iran)

farahmandm@outlook.com or m_farahmand@ razi.tums.ac.ir 
pears to cause clinical disease only in individuals with relative or absolute immunodeficiency such as pregnancy, cancer, HIV infection, those receiving chemotherapy, bone marrow, and solid organ transplant recipients [4]. Among solid organ transplant recipients, BKV infection is mostly limited to renal transplantations that results in viruria in $30-50 \%$ and viremia in $13-22 \%$ of cases [5]. $\mathrm{BKV}$ infection in renal allograft recipients can cause hemorrhagic cystitis, tubulointerstitial nephritis, ureteric stenosis, transient renal dysfunction, and BKV nephropathy (BKVN) [6]. BKVN occurs in about $5 \%$ of renal transplant (RT) recipients with irreversible graft failure developing in $45 \%$ of affected patients [7, 8]. Many risk factors for the development of BKVN have been proposed, including older recipient age, male gender, rejection episodes, degree of human leukocyte antigen mismatching, and BKV serostatus [9]. Detection of BKV DNA in plasma by noninvasive PCR assay has been suggested as a surrogate marker of BKVN [10]. Current recommendations for screening BK viral load in the plasma are largely opinion-based but in general suggest monthly for the first 6 months of kidney transplantation then every 3 months for the first 2 years following the transplantation $[1,11]$. The prevalence and significance of BKV in RT recipients remain to be clarified in the Iranian population. The purpose of this review is to summarize the available published literature to estimate pooled prevalence of BKV infection in RT recipients from a number of studies conducted in Iran.

\section{Methods}

\section{Search Strategy}

An extensive literature review for all published studies up to November 2019 with no specified start date was carried out. Databases such as PubMed, Web of Science, Scopus, Science Direct, Google Scholar, Embase, and Persian national databases (Magiran [www.Magiran.com], Scientific Information Database [SID] [www.sid.ir], IranMedex, and Iran Doc) were used to conduct a comprehensive search of studies in the field of BKV infection in RT patients. To this purpose, we used and combined several search terms of BKV. The following search keyword combination was used (polyomavirus, BK or polyomavirus hominis 1 or BK polyomavirus or human polyomavirus BK or polyomavirus BK) and (prevalence or seroprevalence or epidemiological study or immunity or antibody or seroepidemiology or frequency) and (Iran or Persia or "I.R. Iran" or "I R. Iran" or Islamic Republic of Iran) and (renal transplantation or renal transplantations or transplantations, renal or transplantation, renal or grafting, kidney or kidney grafting or transplantation, kidney or kidney transplantations or transplantations, kidney).

\section{Study Selection}

All studies which aimed at the detection of BKV infection in the $\mathrm{RT}$ recipients in the Iranian population were included. Of the total publications, irrelevant data, duplicate, and similar ones were identified and excluded based on title and abstract. Publications with the same data but in both English and Persian languages were removed in the next step. Full-length articles, short articles, and conference abstracts were allowed. Full-texts of the relevant studies were then cross-checked by researchers independently and reached a consensus on all items.

\section{Data Extraction}

The following details and information were obtained from each included article: first author, year of publication, sample size, gender, city, BK detection methods, and overall BK prevalence.

\section{Inclusion/Exclusion Criteria}

Apparently, original articles presenting data on the prevalence of BKV infection in the RT recipients in Iran were considered. Some studies were excluded from the analysis due to the following reasons: study that considered RT candidates and those which considered hemodialysis patients. Furthermore, review articles, letters, prospective studies, and case reports were excluded.

\section{Quality Assessment}

The 2 reviewers checked the quality of included studies. All included studies for this meta-analysis were critically appraised using the AXIS tool [12]. The checklist composed of 20 questions covering different methodological perspectives, which the reviewers answered 18 questions to select eligible studies to include in the main meta-analysis. Two questions about nonresponders which were not related to the chosen studies were not answered. Indeed, the "Yes" answer to each question got the point.

\section{Statistical Analysis}

The proportion of BKV in RT recipients was pooled using the inverse variance approach, based on a random-effect model (DerSimonian-Laird weights method) [13]. A logit transformation was used to stabilize the variation of proportions. The Clopper-Pearson method was used to calculate the confidence interval for individual studies [14]. Continuity correction of 0.5 was applied in studies with 0 cell frequencies statistical heterogeneity was measured using the $I^{2}$ test. The meta-analysis was performed with the $\mathrm{R}$ version 3.4 .2 (September 28, 2017) [15], package "meta" [16].

\section{Results}

\section{Search Results}

A flowchart of the literature search and study selection is shown in Figure 1. Following careful article evaluation and the described exclusion/inclusion process, 14 relevant records with 1,578 subjects remained within protocol eligibility criteria, and their information was summarized in Table 1 . These 14 articles evaluated 1,660 specimens for the presence of BKV. 


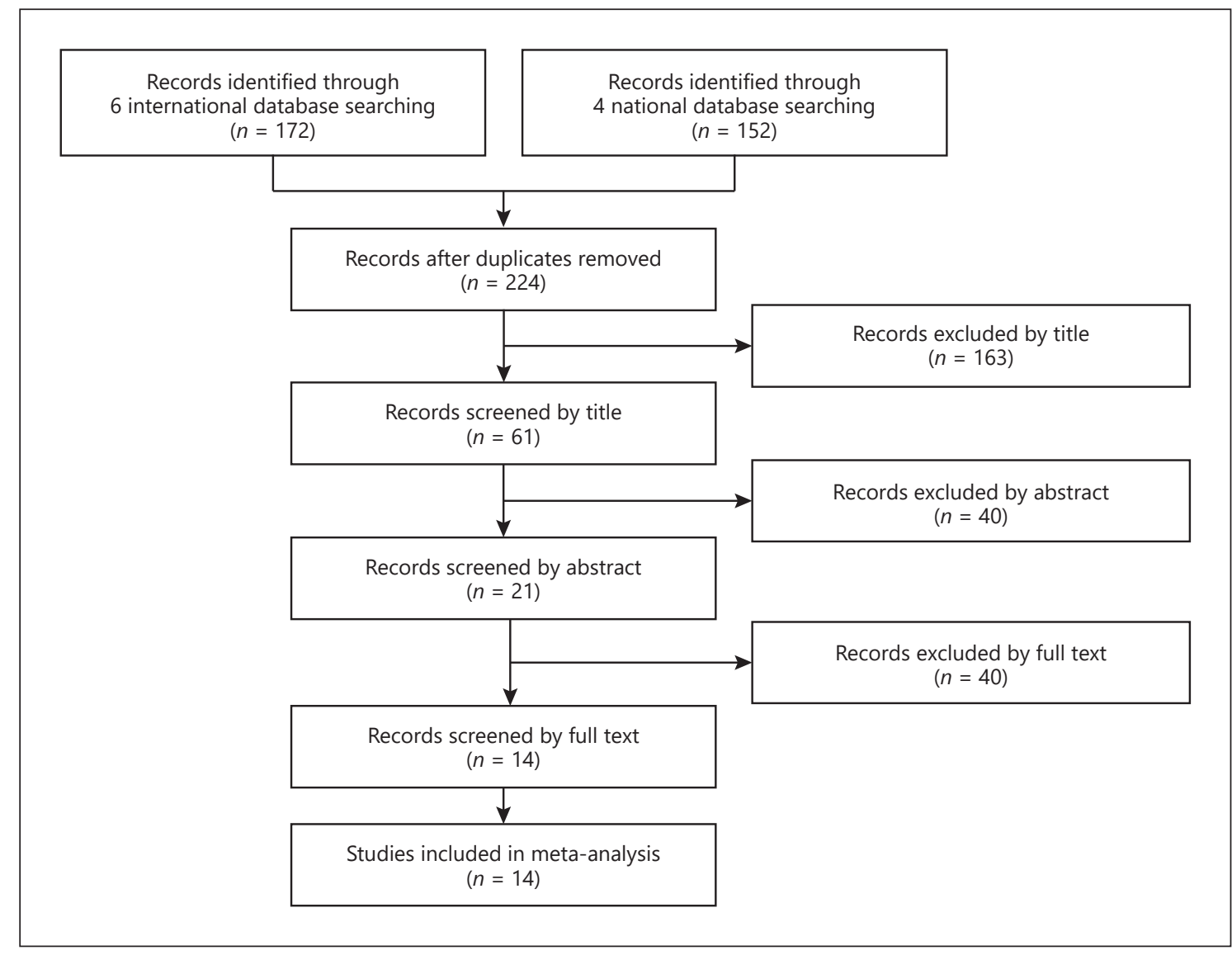

Fig. 1. Flowchart of selection process. The course of the systematic literature review on BKV prevalence in RT recipients in Iran. $\mathrm{RT}$, renal transplant; BKV, BK virus.

Fig. 2. Forest plot diagram of 14 studies showing positivity rate of BKV infection in $\mathrm{RT}$ recipient patients in Iranian population (first author and year of publication). RT, renal transplant; $\mathrm{BKV}, \mathrm{BK}$ virus; $\mathrm{CI}$, confidence interval.

\begin{tabular}{|c|c|c|c|}
\hline Study & & $\begin{array}{l}\text { Proportion, } \\
95 \% \mathrm{Cl}\end{array}$ & $\begin{array}{l}\text { Weight } \\
\%\end{array}$ \\
\hline Ghafari, 2008 & + & $0.13[0.08 ; 0.19]$ & 7.5 \\
\hline Samarbasf-Zadeh, 2009 & 1 & $0.59[0.47 ; 0.70]$ & 7.5 \\
\hline Shenagari, 2010 & 1 & $0.40[0.26 ; 0.56]$ & 7.2 \\
\hline Soleymanian, 2010 & + & $0.01[0.00 ; 0.06]$ & 3.6 \\
\hline Nasiri, 2011 & $\frac{1}{1}$ & $0.26[0.18 ; 0.37]$ & 7.5 \\
\hline Imani, 2011 & +1 & $0.20[0.14 ; 0.28]$ & 7.6 \\
\hline Motazakker, 2012 & + & $0.10[0.05 ; 0.17]$ & 7.2 \\
\hline Pezeshgi, 2012 & +1 & $0.29[0.14 ; 0.48]$ & 6.7 \\
\hline Kaydani, 2015 & 1 & $0.42[0.33 ; 0.51]$ & 7.7 \\
\hline Pakfetrat, 2015 & 1 & $0.26[0.18 ; 0.35]$ & 7.6 \\
\hline Emami, 2017 & + & $0.09[0.04 ; 0.15]$ & 7.2 \\
\hline Shenagari, 2017 & 1 & $0.49[0.39 ; 0.59]$ & 7.7 \\
\hline Zareei, 2017 & + & $0.09[0.05 ; 0.13]$ & 7.6 \\
\hline Kariminik, 2018 & 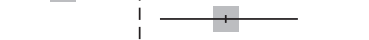 & $0.40[0.27 ; 0.53]$ & 7.4 \\
\hline \multirow[t]{2}{*}{ Overall $R^{2}=93 \%, p<0.01$} & 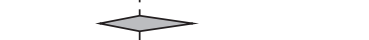 & $0.23[0.15 ; 0.33]$ & 100.0 \\
\hline & $\begin{array}{lllllll} & & & & 1 & 1 & 1 \\
0.1 & 0.2 & 0.3 & 0.4 & 0.5 & 0.6\end{array}$ & & \\
\hline
\end{tabular}

BK Virus in Renal Transplant Recipients in Iran 


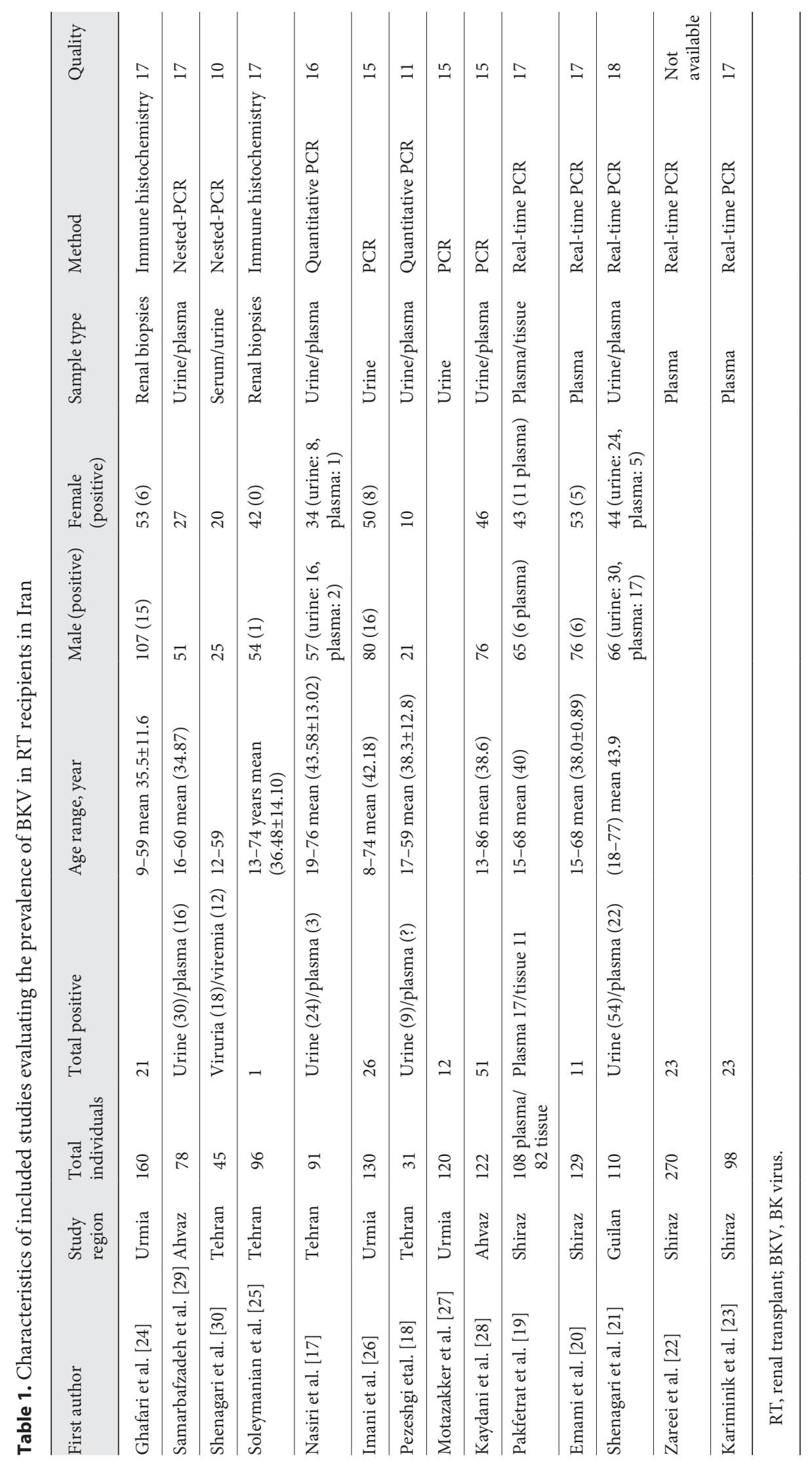


Fig. 3. Forest plots of BKV prevalence in RT patients in the males and females population. $\mathrm{RT}$, renal transplant; $\mathrm{BKV}, \mathrm{BK}$ virus; $\mathrm{CI}$, confidence interval.

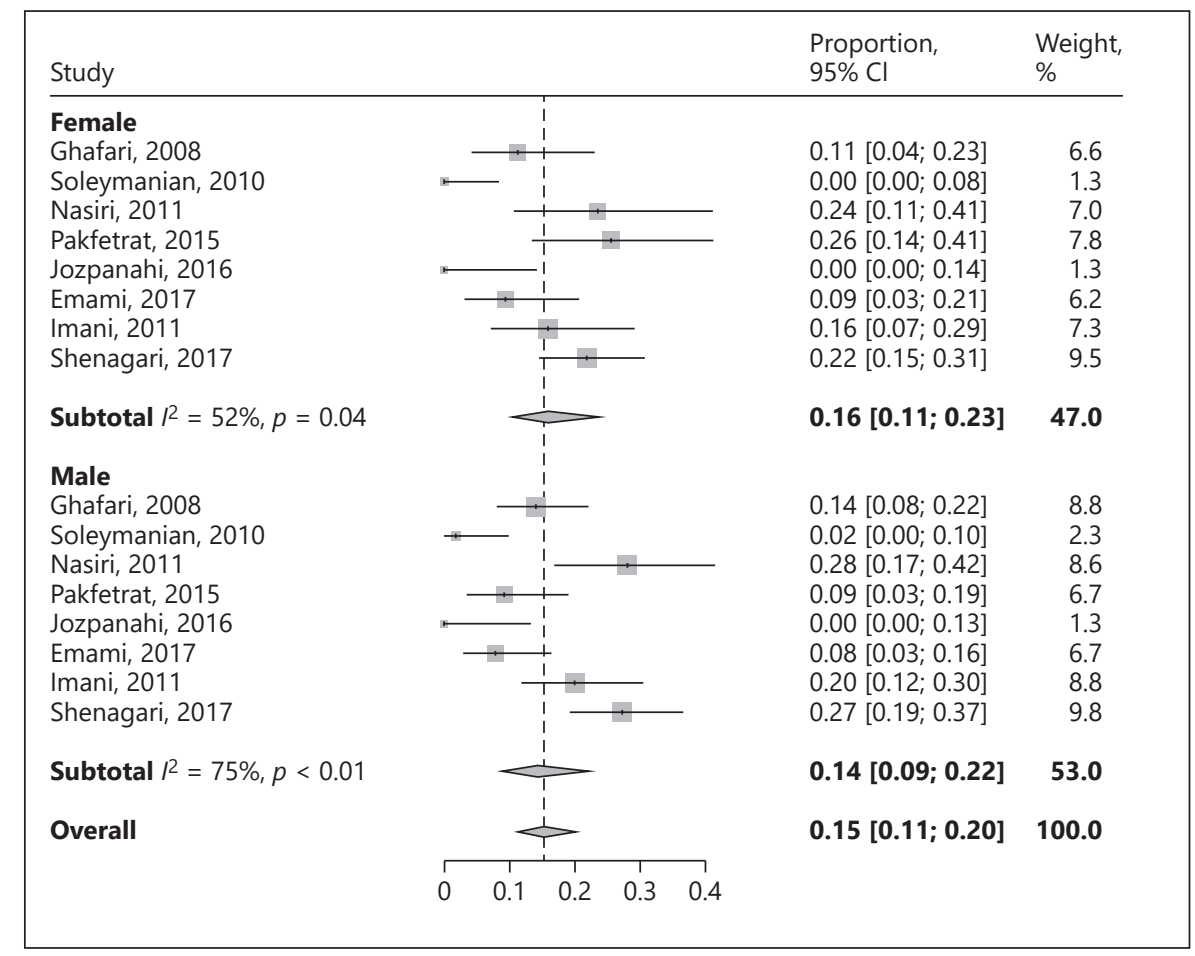

\section{Prevalence of $B K V$}

A total of 383 individuals out of 1,660 were BKV positive. Due to substantial heterogeneity among reported studies $\left(I^{2}=93 \%, p<0.01\right)$, random-effect meta-analysis (REM) was performed. The overall pooled prevalence of BKV infection among the Iranian population was $23 \%$ (95\% CI; 15-33\%). It should be noted that the prevalence of BKV in plasma samples ranges from 3 to $40 \%$, in renal biopsies ranges from 1 to $13 \%$, and in urine samples ranges from 10 to $49 \%$ in these studies. The forest plot in Figure 2 suggests a high heterogeneity between the studies.

\section{Subgroup Analysis}

This study analyzed pooled prevalence of BKV based on gender, method of detection, city, and sample type. Classification of participants according to gender shows high prevalence of BKV among females $\left(16 \%, I^{2}=52, p=\right.$ 0.04 vs. $14 \%, I^{2}=75 \%, p<0.01$, respectively) (Fig. 3). Seven studies employed real-time PCR $\left(24 \%, I^{2}=93, p<\right.$ $0.01)$ [17-23], 2 immunohistochemistry $\left(5 \%, I^{2}=85, p<\right.$ $0.01)[24,25], 3$ PCR $\left(22 \%, I^{2}=94 \%, p<0.01\right)$ [26-28], and 2 nested-PCR methods (50\%, $\left.I^{2}=75, p=0.04\right)$ [29, 30] (Fig. 4). Pooled prevalence of BKV from 5 cities among Iranian population was as follows: 4 studies from Tehran $\left(22 \%, I^{2}=81 \%, p<0.01\right)[17,18,25,30], 4$ studies from Shiraz $\left(18 \%, I^{2}=93 \%, p<0.01\right)[19,20,22,23], 1$ study from Ahvaz (42\%) [28], 3 studies from Urmia (14\%, $\left.I^{2}=62 \%, p=0.07\right)[24,26,27]$, and 1 study from Guilan (49\%) [21] (Fig. 5). Since the study by Samarbafzadeh et al. [29] examined samples from Tehran, Shiraz, and Ahvaz, this study excluded from the city subgroup analysis. The majority of articles analyzed plasma sample alone or in combination with other type of specimens. Two studies solely used biopsy tissues [24, 25], 2 studies solely used plasma [20,22, 23], 5 studies used a combination of plasma and urine [17, 18, 21, 28, 29], 1 study used plasma plus biopsy tissue [19], 1 study used serum plus urine [30], and 2 study used urine alone $[26,27]$. Overall, the prevalence of BKV in plasma was $\left(16 \%, I^{2}=86 \%, p<0.01\right)$, in renal biopsies was $\left(10 \%, I^{2}=71 \%, p=0.03\right)[19,24,25]$, and in urine was $\left(29 \%, I^{2}=88 \%, p<0.01\right)[17,18,21,26,27,29$, 30] (Fig. 6).

\section{Discussion}

This systematic review of 14 published studies from various geographical regions in Iran allowed us to estimate the prevalence of BKV infection in RT recipients. Our analysis revealed the overall pooled BKV positivity rate of $23 \%$. This regional estimate was derived using very 
Fig. 4. Forest plots of BKV prevalence in RT patients by method of detection. RT, renal transplant; $\mathrm{BKV}, \mathrm{BK}$ virus; $\mathrm{CI}$, confidence interval.

\begin{tabular}{|c|c|c|c|}
\hline Study & & $\begin{array}{l}\text { Proportion, } \\
95 \% \mathrm{Cl}\end{array}$ & $\begin{array}{l}\text { Weight, } \\
\%\end{array}$ \\
\hline \multicolumn{4}{|l|}{ Immunohistochemistry } \\
\hline Ghafari, 2008 & $\rightarrow 1$ & $0.13[0.08 ; 0.19]$ & 7.5 \\
\hline \multirow[b]{2}{*}{ Subtotal $R^{2}=85 \%, p<0.01$} & + & $0.01[0.00 ; 0.06]$ & 3.6 \\
\hline & $<$ & $0.05[0.00 ; 0.39]$ & 11.1 \\
\hline \multicolumn{4}{|l|}{ Nested-PCR } \\
\hline Samarbasf-Zadeh, 2009 & 1 & $0.59[0.47 ; 0.70]$ & 7.5 \\
\hline Shenagari, 2010 & 1 & $0.40[0.26 ; 0.56]$ & 7.2 \\
\hline Subtotal $R^{2}=75 \%, p=0.04$ & $\longrightarrow$ & $0.50[0.32 ; 0.68]$ & 14.7 \\
\hline \multicolumn{4}{|l|}{ PCR } \\
\hline Imani, 2011 & -1 & $0.20[0.14 ; 0.28]$ & 7.6 \\
\hline Motazakker, 2012 & -1 & $0.10[0.05 ; 0.17]$ & 7.2 \\
\hline \multirow{2}{*}{$\begin{array}{l}\text { Kaydani, } 2015 \\
\text { Subtotal } R^{2}=94 \%, p<0.01\end{array}$} & $\longrightarrow$ & $0.42[0.33 ; 0.51]$ & 7.7 \\
\hline & $\frac{1}{1}$ & $0.22[0.09 ; 0.44]$ & 22.5 \\
\hline \multicolumn{4}{|l|}{ Real time PCR } \\
\hline Nasiri, 2011 & $\frac{1}{1}$ & $0.26[0.18 ; 0.37]$ & 7.5 \\
\hline Pezeshgi, 2012 &,+ & $0.29[0.14 ; 0.48]$ & 6.7 \\
\hline Pakfetrat, 2015 & +1 & $0.26[0.18 ; 0.35]$ & 7.6 \\
\hline Emami, 2017 & + & $0.09[0.04 ; 0.15]$ & 7.2 \\
\hline Shenagari, 2017 & + & $0.49[0.39 ; 0.59]$ & 7.7 \\
\hline Zareei, 2017 & + & $0.09[0.05 ; 0.13]$ & 7.6 \\
\hline Kariminik, 2018 & 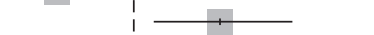 & $0.40[0.27 ; 0.53]$ & 7.4 \\
\hline Subtotal $R^{2}=93 \%, p<0.01$ & & $0.24[0.13 ; 0.39]$ & 51.6 \\
\hline Overall & $i_{1}^{i}$ & $0.23[0.15 ; 0.33]$ & 100.0 \\
\hline & $\begin{array}{lllllll} & & 1 & & 1 & 1 & \\
0.1 & 0.2 & 0.3 & 0.4 & 0.5 & 0.6\end{array}$ & & \\
\hline
\end{tabular}

Fig. 5. Forest plots of BKV prevalence in RT patients in different cities of Iran. RT, renal transplant; $\mathrm{BKV}, \mathrm{BK}$ virus; $\mathrm{CI}$, confidence interval.

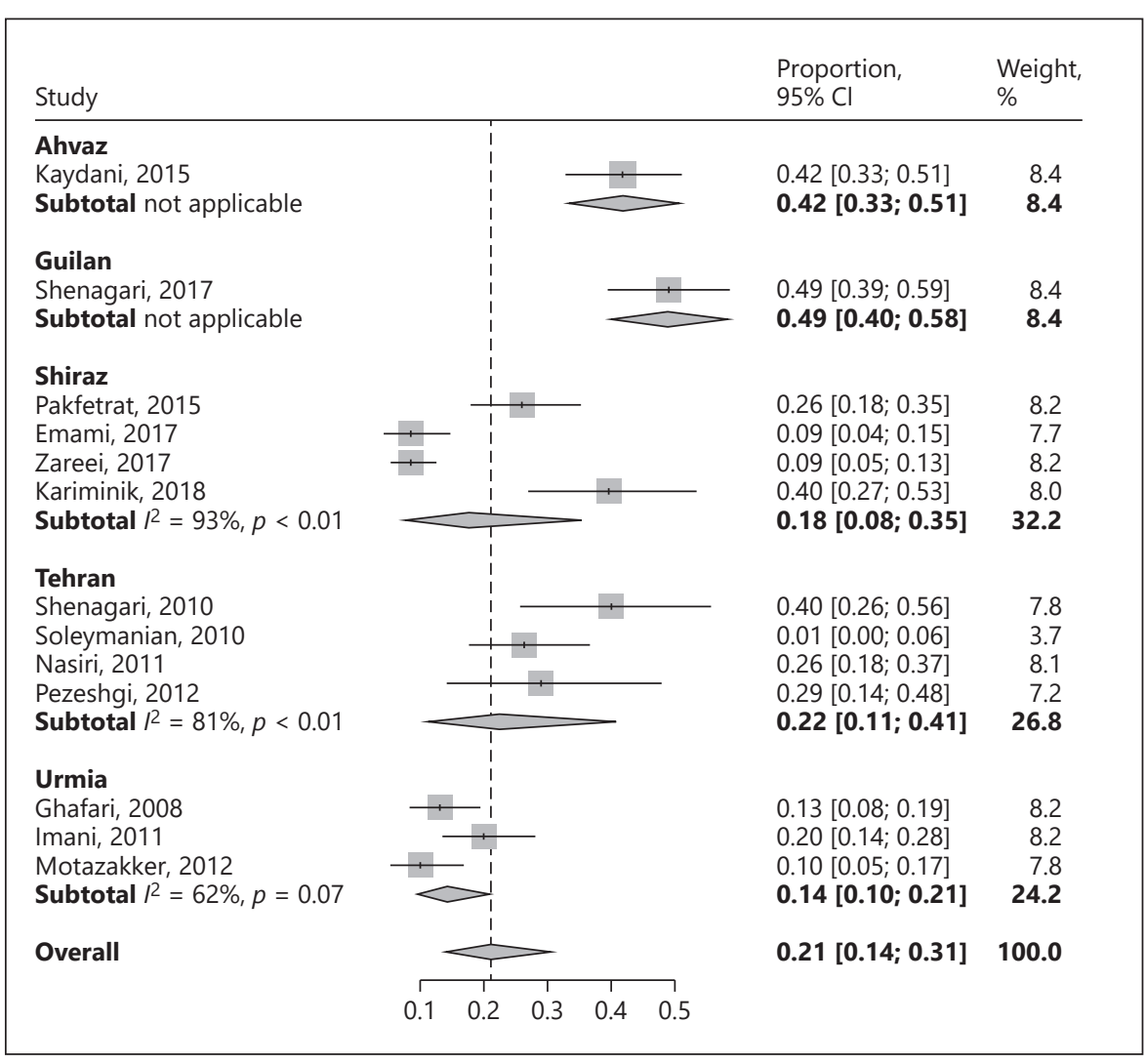

Shatizadeh Malekshahi/Soleimanjahi/ Dorostkar/Salimi/Farahmand 
Fig. 6. Forest plots analysis of BKV prevalence in RT patients by sample type. RT, renal transplant; $\mathrm{BKV}$, BK virus; $\mathrm{CI}$, confidence interval.

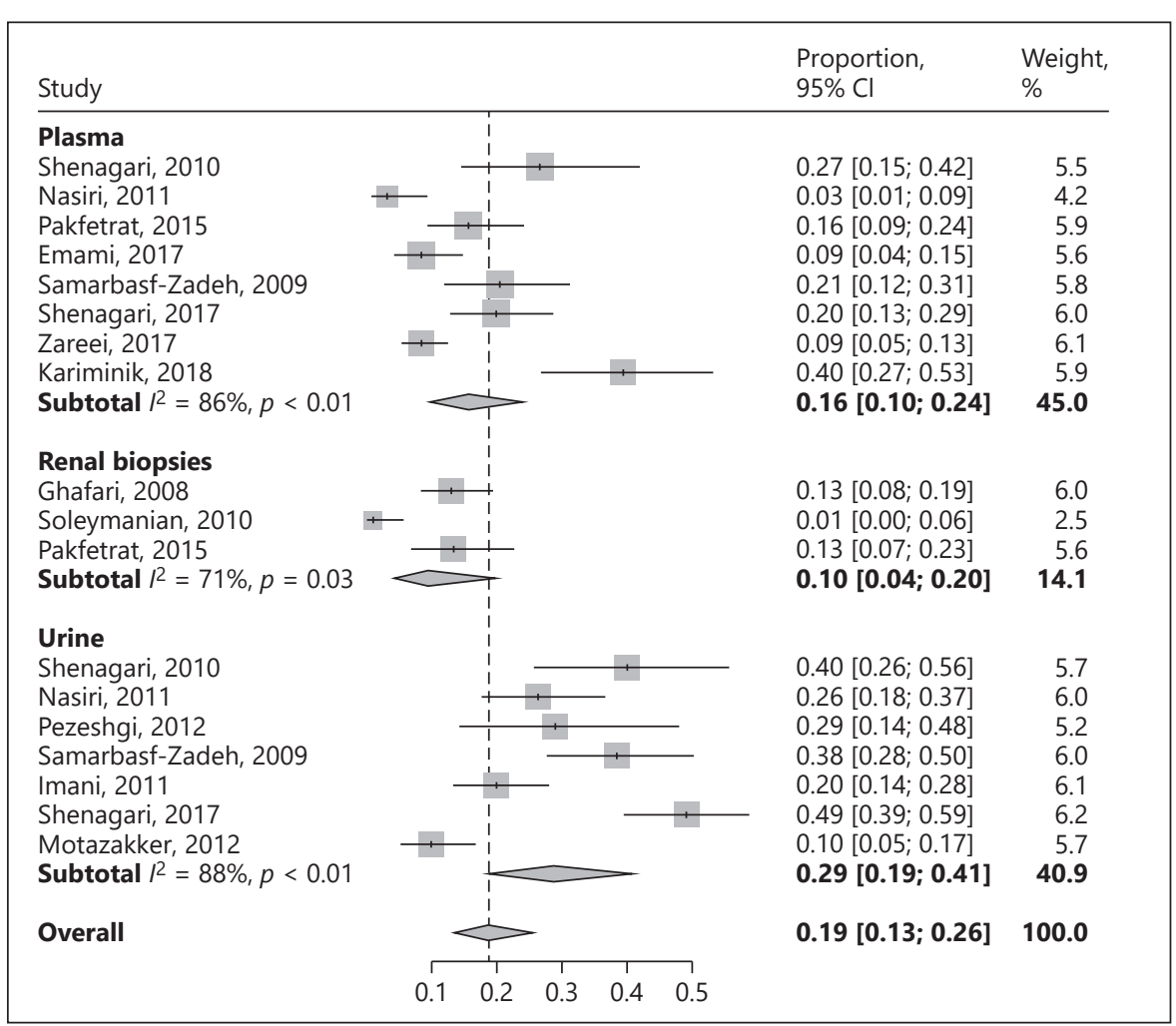

heterogeneous sets of studies in terms of various sources $\left(I^{2}>75 \%\right.$ in many analyses). Comparing these studies revealed that the prevalence of BKV in plasma samples ranges from 3 to $40 \%$, in renal biopsies $1-13 \%$, and in urine samples $10-49 \%$. This variability in the reported prevalence of infection may reflect differences in study methods used, several technical aspects (sensitivity of the assays and quality of the DNA), and type of sample examined (urine, serum, plasma, and tissue biopsy). Given this heterogeneity, random-effect models were adopted to ensure valid estimation with the available information. The prevalence of BKV was found to be different based on geographic regions in Iran. This may reflect real regional differences in the BKV detection rate but may also be related to variations in research design, sample size, and type of samples as BKV more detected among plasma samples than histological samples. More investigations are needed in many unanalyzed regions of Iran to estimate the prevalence of BKV in Iranian RT recipients reliably.

BKV infection represents a potential threat to longterm kidney transplant success, and progression to BKVN may result in graft loss $[31,32]$. It should be mentioned that in the current analysis, a few proportions of recipi- ents experienced BKVN. Ghafari et al. [24] reported BKVN among 21 (13.1\%) out of 160 patients, and graft loss occurred in $57.1 \%$ of BKVN versus $12.2 \%$ of nonBKVN subjects. Additionally, a low prevalence of BKVN reported in Soleymanian et al. [25] study (1 [1.04\%] out of 96 recipients). It is unclear whether BKV originates from the allograft or reactivated by immunosuppression in the recipient. Of specific interest is the recent report that suggested the donor origin of BKV infection in RT recipients [33].

Historically, BKV particles can be identified in both blood and urine. Biopsy should be performed for either evidence of BKV alone or in the setting of renal dysfunction in the presence of concomitant BKV viruria or viremia [34]. Viral load quantitation by PCR in the plasma or urine is the standard clinical tool for monitoring BKV reactivation [35]. In the current systematic review, there was no uniform detection method used in these studies, thus, raising the possibility of underestimation in prevalence investigation.

This systematic review also suggests that the BKV infection rate was slightly higher in women than men $(16 \%$, $p=0.04$ vs. $14 \%, p<0.01$, respectively). Since the study populations are unequally distributed in terms of gender, 
high numbers of infected women may lead to false positivity rates in women. Although immunosuppression is the most consistent risk factor for the development of $\mathrm{BKVN}$, male gender, and older recipient age are the other hypothesized risk factors in this regard [36]. Additionally, BKV genotype-specific neutralizing antibody titer was recently discovered as an important risk factor for BKVN prediction [37]. Another recent study introduced BKVgenotyping as an additional method for risk assessment for BKVN [38].

BKVs are classified into 4 subtypes, and subtype $\mathrm{I}$ is the most commonly identified 1 worldwide with a prevalence range of $46-82 \%$ [39]. BKV subtype IV is found primarily in East Asia and Europe and makes up $15 \%$ of BKV infections. Subtypes II and III are occurring less frequently throughout the world [40, 41]. Little information is available on BKV subtypes in RT recipients in Iran. Only 2 studies from Iran reported data on BKV subtypes. In 2012, Motazakker et al. [27] published the first data on BKV subtypes reporting subtype I the most frequently detected in RT recipients. In another study in 2015 by Kaydani et al. [28], subtype I was the most common $(94.11 \%)$, and subtype IV was second in frequency (5.89\%). The much higher prevalence estimate of BKV serotype I is supported by the previous studies [42], which show that BKV infection is associated with this subtype. A better knowledge of viral subtypes is essential for tracing infection trails in epidemiologic investigations [41]. Future studies are needed in order to determine the causative roles of BKV subtypes in the development of clinical syndromes and nephropathy.

Due to the lack of detailed reporting of the study results by age-groups, subgroup analysis by age could not be performed. In this regard, we were not able to examine whether BKV presence varied by age as these data were limited in included studies. As mentioned before, older recipient age is hypothesized as a risk factor for the development of BKVN but has not uniformly observed in all studies.

\section{Conclusion}

In summary, BKV infection remains a major cause of graft loss and an important clinical problem following renal transplantation. Our analysis provides a preliminary estimate of the epidemiology of BKV infection in RT recipients in Iran. We believe these results stimulate a strong need for large, methodologically rigorous epidemiological studies of BKV infection in different unanalyzed regions in Iran. Early detection of BKV in RT recipients helps timely nephropathy diagnosis and prevents graft loss. There is room for research regarding the detection of other viruses causing coinfection with BKV or having the same clinical presentation. Moreover, assessing the correlations between the presence of different viral subtypes and the severity and course of clinical infection deserve further investigation.

\section{Statement of Ethics}

This research was conducted ethically in accordance with the World Medical Association Declaration of Helsinki.

\section{Conflict of Interest Statement}

The authors report no conflicts of interest.

\section{Funding Source}

As this is a meta-analysis, there has been no financial support.

\section{Author Contributions}

Somayeh Shatizadeh Malekshahi contributed in design of the study and writing the paper, Mohammad Farahmand performed the data extraction and analyses of the data, Horieh Soleimanjahi reviewed the paper, and comments were included, Fariba Dorostkar and Vahid salami co-worked on data extraction.

\section{References}

1 Viswesh V, Yost SE, Kaplan B. The prevalence and implications of BK virus replication in non-renal solid organ transplant recipients: a systematic review. Transplant Rev. 2015; 29(3): 175-80.

2 Dropulic LK, Jones RJ. Polyomavirus BK infection in blood and marrow transplant recipients. Bone Marrow Transplant. 2008; 41(1):11-8.
3 Polo C, Pérez JL, Mielnichuck A, Fedele CG, Niubò J, Tenorio A. Prevalence and patterns of polyomavirus urinary excretion in immunocompetent adults and children. Clin Microbiol Infect. 2004;10(7):640-4.

4 Barraclough KA, Isbel NM, Staatz CE, Johnson DW. BK virus in kidney transplant recipients: the influence of immunosuppression. J Transplant. 2011;2011:750836.
Shatizadeh Malekshahi/Soleimanjahi/ Dorostkar/Salimi/Farahmand 
5 Jacobi J, Prignitz A, Büttner M, Korn K, Weidemann A, Hilgers KF, et al. BK viremia and polyomavirus nephropathy in 352 kidney transplants; risk factors and potential role of mTOR inhibition. BMC Nephrol. 2013; 14(14):207.

6 Jozpanahi M, Ramezani A, Ossareh S, Banifazl M, Bavand A, Mamishi S, et al. BK viremia among Iranian renal transplant candidates. Iran J Pathol. 2016;11(3):210-5.

7 Cimbaluk D, Pitelka L, Kluskens L, Gattuso P. Update on human polyomavirus BK nephropathy. Diagn Cytopathol. 2009;37(10): 773-9.

8 van Aalderen MC, Heutinck KM, Huisman C, ten Berge IJ. BK virus infection in transplant recipients: clinical manifestations, treatment options and the immune response. Neth J Med. 2012;70(4):172-83.

9 Tremolada S, Akan S, Otte J, Khalili K, Ferrante $\mathrm{P}$, Chaudhury PR, et al. Rare subtypes of $\mathrm{BK}$ virus are viable and frequently detected in renal transplant recipients with BK virus-associated nephropathy. Virology. 2010;404(2): $312-8$.

10 Viscount HB, Eid AJ, Espy MJ, Griffin MD, Thomsen KM, Harmsen WS, et al. Polyomavirus polymerase chain reaction as a surrogate marker of polyomavirus-associated nephropathy. Transplantation. 2007;84(3):340-5.

11 Boan P, Hewison C, Swaminathan R, Irish A, Warr K, Sinniah R, et al. Optimal use of plasma and urine $\mathrm{BK}$ viral loads for screening and predicting BK nephropathy. BMC Infect Dis. 2016; 16:342.

12 Downes MJ, Brennan ML, Williams HC, Dean RS. Development of a critical appraisal tool to assess the quality of cross-sectional studies (AXIS). BMJ Open. 2016;6(12): e011458.

13 DerSimonian R, Laird N. Meta-analysis in clinical trials. Control Clin Trials. 1986;7(3): $177-88$.

14 Newcombe RG. Two-sided confidence intervals for the single proportion: comparison of seven methods. Stat Med. 1998;17(8):857-72.

15 Team, R.C. R. A language and environment for statistical computing [Internet]. Vienna, Austria; 2014. 2017.

16 Schwarzer G. Meta: an R package for metaanalysis. R News. 2007;7:40-5.

17 Nasiri S, Ahmadi SF, Lessan-Pezeshki M, Seyfi S, Alatab S. Lack of cytomegalovirus and polyomavirus coexistence in Iranian kidney transplant recipients. Transplant Proc. 2011; 43(2):536-9.

18 Pezeshgi A, Ghods A, Keivani H, Asgari M, Shatty M. Incidence of BK virus nephropathy $(\mathrm{BKVN})$ in renal transplant recipients. Int $\mathrm{J}$ Organ Transplant Med. 2012;3(3):115-8.
19 Pakfetrat M, Yaghobi R, Salmanpoor Z, Roozbeh J, Torabinezhad S, Kadkhodaei S. Frequency of polyomavirus BK infection in kidney transplant patients suspected to nephropathy. Int J Organ Transplant Med. 2015;6(2): 77-84.

20 Emami A, Yaghobi R, Moattari A, Baseri Salehi M, Roozbeh J. Noncoding control region pattern of BK polyomavirus in kidney transplant patients with nephropathy. Exp Clin Transplant. 2017;15(2):150-6.

21 Shenagari M, Monfared A, Eghtedari $\mathrm{H}$, Pourkazemi A, Hasandokht T, Khosravi M, et al. BK virus replication in renal transplant recipients: analysis of potential risk factors may contribute in reactivation. J Clin Virol. 2017; 96:7-11.

22 Zareei N, Miri H, Karimi M, Afshari A, Geramizadeh B, Roozbeh J, et al. Interferon- $\gamma$ gene expression during polyomavirus $\mathrm{BK}$ infection in kidney transplant patients. 2017.

23 Kariminik A, Yaghobi R, Dabiri S. Association of BK virus infection with CXCL11 gene expression and protein levels in kidney transplant patients. Exp Clin Transplant. 2018; 16(1):50-4.

24 Ghafari A, Lessan-Pezeshki M, Taghizadieh M, Rahimi E. BK polyoma virus nephropathy among Iranian renal transplant recipients. Transplant Proc. 2008;40(1):193-5.

25 Soleymanian T, Rasulzadegan MH, Sotoodeh M, Ganji MR, Naderi G, Amin M, et al. Low prevalence of BK virus nephropathy on nonprotocol renal biopsies in Iranian kidney transplant recipients: one center's experience and review of the literature. Exp Clin Transplant. 2010;8(4):297-302.

26 Imani M, Ghaffari-Moghadam A, Makhdoomi KH, Afshari Taghizadeh A, Motezaker M. Molecular study of BK virus reactivation in urine sample of renal transplant patients. Urmia Med J. 2011;22(4):290-6.

27 Motazakker M, Bagheri M, Imani M. Subtyping of BK virus in Iranian Turkish renal transplant recipients by RFLP-PCR. Maedica. 2012;7(1):10-3

28 Kaydani GA, Makvandi M, Samarbafzadeh A, Shahbazian H, Hamidi Fard M. Prevalence and distribution of $\mathrm{BK}$ virus subtypes in renal transplant recipients referred to Golestan Hospital in Ahvaz, Iran. Jundishapur J Microbiol. 2015;8(3):e16738.

29 Samarbafzadeh AR, Makvandi M, Kaidani GHA, Shahbazian HA, Pourfarziani V, Yaghoubi R, et al. Prevalence of BK virus in renal allograft recipients pre and post transplantation in Iran. Jundishapur J Microbiol. 2009; 2(2):47-52.

30 Shenagari M, Ravanshad M, Hosseini SY, Ghanbari R. Detection and prevalence of polyoma virus BK among Iranian kidney transplant patients by a novel nested-PCR. IRCMJ. 2010;12:631-5.
31 Elfadawy N, Flechner SM, Liu X, Schold J, Tian D, Srinivas TR, et al. The impact of surveillance and rapid reduction in immunosuppression to control BK virus-related graft injury in kidney transplantation. Transpl Int. 2013;26(8):822-32.

32 Mbianda C, El-Meanawy A, Sorokin A. Mechanisms of BK virus infection of renal cells and therapeutic implications. J Clin Virol. 2015;71:59-62.

33 Schmitt C, Raggub L, Linnenweber-Held S, Adams O, Schwarz A, Heim A. Donor origin of BKV replication after kidney transplantation. J Clin Virol. 2014;59(2):120-5.

34 Yi SG, Knight RJ, Lunsford KE. BK virus as a mediator of graft dysfunction following kidney transplantation. Curr Opin Organ Transplant. 2017;22(4):320-7.

35 Ambalathingal GR, Francis RS, Smyth MJ, Smith C, Khanna R. BK polyomavirus: clinical aspects, immune regulation, and emerging therapies. Clin Microbiol Rev. 2017;30(2): 503-28.

36 Sawinski D, Goral S. BK virus infection: an update on diagnosis and treatment. Nephrol Dial Transplant. 2015;30(2):209-17.

37 Solis M, Velay A, Porcher R, Domingo-Calap $\mathrm{P}$, Soulier E, Joly M, et al. Neutralizing antibody-mediated response and risk of BK virusassociated nephropathy. J Am Soc Nephrol. 2018;29(1):326-34

38 Korth J, Anastasiou OE, Bräsen JH, Brinkhoff A, Lehmann U, Kribben A, et al. The detection of BKPyV genotypes II and IV after renal transplantation as a simple tool for risk assessment for PyVAN and transplant outcome already at early stages of BKPyV reactivation. J Clin Virol. 2019;113:14-9.

39 Tang VD, Rockett R, Jeoffreys N, Trung NV, AN HPH, Kok J, et al. BK polyomavirus: a review of the virology, pathogenesis, clinical and laboratory features, and treatment. Future Virol. 2017;12:439-59.

40 Kapusinszky B, Chen SF, Sahoo MK, Lefterova MI, Kjelson L, Grimm PC, et al. BK polyomavirus subtype III in a pediatric renal transplant patient with nephropathy. J Clin Microbiol. 2013;51(12):4255-8.

41 Morel V, Martin E, François C, Helle F, Faucher J, Mourez T, et al. A simple and reliable strategy for BK virus subtyping and subgrouping. J Clin Microbiol. 2017;55(4):117785.

42 Zhong S, Randhawa PS, Ikegaya H, Chen Q, Zheng HY, Suzuki M, et al. Distribution patterns of BK polyomavirus (BKV) subtypes and subgroups in American, European and Asian populations suggest co-migration of BKV and the human race. J Gen Virol. 2009; 90(Pt 1):144-52. 